\title{
Qualidade de sementes de pimenta jalapenho em função da maturação e tempo de permanência nos frutos ${ }^{1}$
}

\author{
Nara Ricci², Ana Cláudia Pacheco ${ }^{2}$, Alysson Sfordi Conde ${ }^{2}$, Ceci Castilho Custódio²
}

\begin{abstract}
Seed quality of jalapeno pepper

according to fruit maturation and post harvest rest

Pepper seeds can show low germination rates and that, together with the unfamiliarity concerning their best harvest time, limits the seeds offering with maximum yield and vigor. This study aimed at evaluating the emergence of jalapeno pepper seeds obtained from fruits harvested at 128 days after sowing, with two maturation stages (green and red) and stored for 0, 7, 14, 21 and 28 days, before the seeds extraction. The seeds physiological quality was evaluated by using the tests of emergence percentage, first emergence counting, emergence rate index and electrical conductivity. It was possible to conclude that, independently of the fruit maturation stage, the post harvest rest of seeds inside the fruit increased their vigor. The post harvest rest for 28 days inside green fruits showed to be ideal for a complete seed development and higher physiological quality.
\end{abstract}

KEY-WORDS: Capsicum annuum L.; harvest time; germination; physiological quality.

\section{INTRODUÇÃO}

A pimenta jalapenho (Capsicum annuum L.) é originária da cidade de Jalapa, no México, e seu sabor medianamente picante possibilita sua utilização tanto para o consumo in natura quanto processado na forma de pó e molhos. Seu cultivo está difundido em muitas regiões do Brasil, pelo fato de ser excelente alternativa de renda para o produtor rural.

As sementes de pimenta podem apresentar baixas taxas de germinação e dormência (Lakshmanan \& Berke 1998), fato que, aliado ao desconhecimento do melhor estádio de colheita das mesmas, limita a oferta de sementes com alto vigor.

Em espécies de crescimento indeterminado como a pimenta, cujo florescimento e frutificação são contínuos, é comum encontrar, na mesma plan-

\section{RESUMO}

As sementes de pimenta podem apresentar baixas taxas de germinação, fato que, aliado ao desconhecimento do melhor estádio de colheita das mesmas, limita a oferta de sementes com máximo rendimento e alto vigor. Este trabalho objetivou avaliar a emergência de sementes de pimenta jalapenho extraídas de frutos colhidos aos 128 dias após o plantio, apresentando dois estádios de maturação (verde e vermelho) e submetidas ao armazenamento por 0, 7, 14, 21 e 28 dias, antes da extração das sementes. A qualidade fisiológica das sementes foi avaliada pelos testes de percentagem de emergência, primeira contagem de emergência, índice de velocidade de emergência e condutividade elétrica. Pôde-se concluir que, independentemente do estádio de maturação dos frutos, a permanência das sementes dentro deles proporcionou aumento de vigor nas sementes. A permanência das sementes por 28 dias, dentro dos frutos colhidos verdes, mostrou-se ideal para que as sementes completassem o seu desenvolvimento e adquirissem maior qualidade fisiológica.

PALAVRAS-CHAVE: Capsicum annuum L.; época de colheita; germinação; qualidade fisiológica.

ta, frutos em diferentes estádios de maturação, o que dificulta determinar a época em que ocorre a maturidade fisiológica das sementes e o momento ideal para a colheita dos frutos (Silva et al. 2009). Segundo Nascimento et al. (2006), para sementes de algumas cultivares de pimenta, a colheita pode ser iniciada, aproximadamente, aos 60 dias após o florescimento, ou quando mais de $80 \%$ dos frutos estiverem mudando de cor.

O melhor estádio de colheita de sementes minimiza os efeitos da deterioração das mesmas, provocados pela permanência prolongada do fruto na planta, além de aumentar a produtividade das sementes, visto que a colheita precoce pode acarretar em grande proporção de sementes imaturas (Vidigal et al. 2009). Entretanto, tem sido demonstrado que, mesmo antes da maturação do fruto (mudança da co-

1. Trabalho recebido em ago./2012 e aceito para publicação em abr./2013 (nº registro: PAT 19639).

2. Universidade do Oeste Paulista (Unoeste), Faculdade de Ciências Agrárias, Presidente Prudente, SP, Brasil.

E-mails: nararicci@hotmail.com, anaclau@unoeste.br, alhysson@hotmail.com,ceci@unoeste.br. 
loração verde para vermelha), as sementes já podem alcançar a maturidade fisiológica, momento, este, em que as mesmas atingem o máximo de germinação e vigor (Silva et al. 2009), devido à formação completa dos sistemas bioquímico, morfológico e estrutural (Nakada et al. 2011).

Em geral, o máximo acúmulo de massa seca é atingido concomitantemente à maturidade fisiológica das sementes, entretanto, estes dois eventos podem não coincidir, observando-se ocorrência variável entre as espécies (Nascimento et al. 2006, Nakada et al. 2011).

De maneira geral, a percentagem de germinação das sementes que não atingiram a maturidade fisiológica e são colocadas para germinar logo após a colheita é menor, se comparadas àquelas cujos testes de germinação são realizados após alguns dias de armazenamento. Tal situação é também observada quando se faz o armazenamento (repouso) dos frutos carnosos de algumas espécies como o pimentão, abóbora, melancia, mamão, berinjela, tomate e pepino (Castro et al. 2008).

Sementes mantidas por determinado período de tempo no fruto, após a colheita, dão continuidade ao processo de maturação, atingindo níveis máximos de germinação e vigor (Dias et al. 2006, Vidigal et al. 2006). Logo, o armazenamento pós-colheita dos frutos, antes da extração das sementes, pode ser um aspecto vantajoso para os produtores de sementes, pois permite colher os frutos ainda imaturos, evitando riscos com possíveis condições desfavoráveis no campo (Barbedo et al. 1994, Martins et al. 2006). Desta maneira, estabelecer o período de tolerância dos frutos após a colheita, em razão do seu grau de maturação, pode auxiliar na racionalização do processo de extração de sementes com máxima qualidade (Silva et al. 2009).

Castro et al. (2008) avaliaram o efeito da idade do fruto e o período de repouso pós-colheita sobre a qualidade de sementes de quiabeiro cv. Santa Cruz-47. Os frutos foram colhidos com 34, 41, 48 e 55 dias após a antese (DAA) e permaneceram em repouso por 14 dias. Os autores concluíram que o armazenamento melhorou o vigor das sementes para qualquer idade do fruto. Para a germinação final, o armazenamento mostrou-se favorável quando os frutos foram colhidos ainda novos (34 e 41 DAA). A elevada qualidade fisiológica das sementes, como resultado da associação vantajosa entre colheita precoce dos frutos e período de armazenamento pós- -colheita, também foi verificada em tomate do grupo Santa Cruz (Vidigal et al. 2006) e abóbora híbrida 'Jabras'(Costa et al. 2006).

A conservação eficiente das sementes, durante seu armazenamento, depende, dentre outros fatores, da sua qualidade inicial, a qual, por sua vez, está diretamente relacionada com a proximidade entre o momento em que as sementes atingem a maturidade fisiológica e o momento em que são colhidas.

Barbedo et al. (1999) avaliaram os efeitos da idade e do repouso pós-colheita, em frutos de pepino, e concluíram que sementes imaturas, retiradas de frutos colhidos precocemente e sem repouso pós-colheita, perderam totalmente a capacidade germinativa, no segundo ano de armazenamento.

Nesse contexto, este trabalho objetivou avaliar as características fisiológicas de sementes de pimenta jalapenho, em função do período de permanência das sementes dentro dos frutos antes da extração, comparando-se sementes provenientes de frutos verdes e vermelhos.

\section{MATERIAL E MÉTODOS}

A pesquisa foi conduzida no Laboratório de Sementes da Universidade do Oeste Paulista (Unoeste), em Presidente Prudente (SP). Os frutos de pimenta jalapenho (Capsicum annuum), cultivar Grande, foram coletados no município de Anhumas

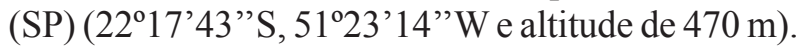
O plantio das mudas ocorreu em 17/05/2010 e a colheita dos frutos foi realizada em 22/09/2010 (aos 128 dias após o plantio - DAP). Neste momento, as plantas apresentavam frutos em diferentes estádios de maturação e a seleção dos mesmos ocorreu de acordo com a coloração, separando-se grupos de frutos apresentando coloração completamente verde e vermelha.

As sementes foram extraídas manualmente, com o auxílio de um estilete, para a abertura dos frutos, sendo a caracterização inicial das sementes efetuada por meio da avaliação da percentagem de emergência (aos 7, 14 e 21 dias após a semeadura DAS) e do índice de velocidade de emergência (IVE).

Os frutos verdes e vermelhos foram submetidos a diferentes períodos de armazenamento, após a colheita $(0,7,14,21$ e 28 dias), durante os quais os mesmos permaneceram em laboratório, sob condições ambientais. Ao término de cada período, as sementes foram extraídas e submetidas à secagem em 
estufa com circulação forçada de ar, por 48 horas, a $25^{\circ} \mathrm{C}$, até atingirem $10 \%$ de umidade.

Os tratamentos foram constituídos pela interação entre os fatores estádio de maturação (coloração verde e vermelha) e período de armazenamento dos frutos/períodos de permanência das sementes dentro dos frutos $(0,7,14,21$ e 28 dias após a colheita), estabelecendo-se um delineamento experimental inteiramente casualizado, com 10 tratamentos e quatro repetições.

O efeito dos tratamentos foi avaliado pelo grau de umidade das sementes, condutividade elétrica, percentagem de emergência na primeira contagem (7 DAS), emergência total (21 DAS) e índice de velocidade de emergência (IVE).

Para a determinação do grau de umidade, foram utilizadas duas subamostras de 100 sementes, para cada tratamento (após a retirada dos frutos e secagem em estufa). As subamostras foram colocadas em latas de alumínio (5,0 cm de diâmetro), as quais seguiram para a estufa, após serem pesadas (massa úmida), onde permaneceram à temperatura de $105 \pm 3^{\circ} \mathrm{C}$, por 24 horas. Após este período, as latas com as sementes foram novamente pesadas, para a obtenção da massa seca (Brasil 2009).

Para análise da condutividade elétrica, foram utilizados copos plásticos contendo $75 \mathrm{~mL}$ de água deionizada, nos quais foram adicionadas 100 sementes de cada tratamento, previamente pesadas (em quatro repetições), que permaneceram por 24 horas, a $25^{\circ} \mathrm{C}$, em germinador. Em seguida, os copos foram retirados da estufa, para a realização de leitura da condutividade elétrica de cada solução, com o auxílio de um condutivímetro, sendo os resultados expressos em $\mathrm{mS} \mathrm{cm}^{-1} \mathrm{~g}^{-1}$.

Após a extração dos frutos e secagem das sementes, 200 sementes foram semeadas em bandejas de polietileno de duzentas células, utilizando-se substrato comercial $\left(\right.$ Bioplant $^{\circledR}$ ). Cada tratamento foi composto por quatro subamostras de 50 sementes e as bandejas foram mantidas em laboratório (com temperatura média de $25^{\circ} \mathrm{C}$ e umidade relativa média de $80 \%$ ). As contagens de emergência ocorreram aos 7, 14 e 21 DAS, sendo expressas em percentagem (Brasil 2009). Foram consideradas somente as plântulas normais que emergiram e que apresentavam o cotilédone aberto. O índice de velocidade de emergência (IVE) foi determinado de acordo com a fórmula IVE $=n 1 / 7+n 2 / 14+$ $\mathrm{n} 3 / 21$, em que $n 1, \mathrm{n} 2$ e $\mathrm{n} 3=$ número de sementes germinadas, e 7, 14 e 21 foram os dias de avaliação (Maguire 1962). Os resultados foram expressos em percentagem.

Foi realizada análise de variância para todos os testes, utilizando-se o programa estatístico Assistat (Silva 2010) e considerando-se o arranjo fatorial de dois estádios de maturação (frutos verdes e vermelhos) e cinco períodos de armazenamento pós-colheita dos frutos $(0,7,14,21$ e 28 dias). Para a comparação entre as médias, empregou-se o teste Tukey, a 5\%. Realizou-se análise de regressão para os níveis do fator tempo de armazenamento pós-colheita dos frutos. Optou-se pelo modelo mais simples, com maior coeficiente de determinação $\left(\mathrm{R}^{2}\right)$.

\section{RESULTADOS E DISCUSSÃO}

Na caracterização inicial das sementes, pôde-se observar que a emergência das sementes retiradas dos frutos verdes e vermelhos apresentou valores significativamente diferentes (Tabela 1). A emergência total (aos 21 DAS) das sementes retiradas dos frutos vermelhos se mostrou superior, em relação à emergência das sementes provenientes dos frutos verdes $(80,5 \%$ e $43 \%$, respectivamente), devido ao estágio mais avançado de desenvolvimento das primeiras. Estes resultados estão em concordância com os obtidos por Queiroz et al. (2011), os quais afirmaram que as sementes retiradas de frutos imaturos de pimenta apresentam baixa germinação, como resultado do aumento na intensidade da dormência, com o decréscimo da idade do fruto.

A indução de dormência primária está relacionada ao maior conteúdo endógeno de ácido abscísico (ABA) presente na semente imatura, embora a manutenção da dormência nem sempre seja dependente da presença deste hormônio, pois, durante a maturação, os teores de ABA reduzem-se a valores baixos, ou mesmo nulos (Kerbauy 2008).

Tabela 1. Caracterização inicial das sementes de pimenta jalapenho retiradas de frutos verdes e vermelhos (Presidente Prudente, SP, 2012).

\begin{tabular}{lcc}
\hline \multicolumn{1}{c}{ Maturação } & Emergência total (\%) & IVE \\
\hline Fruto verde & $43,5 \mathrm{~b}^{1}$ & $2,45 \mathrm{~b}$ \\
Fruto vermelho & $80,5 \mathrm{a}$ & $5,21 \mathrm{a}$ \\
\hline $\mathrm{F}$ & $109,52^{* *}$ & $83,45 * *$ \\
$\mathrm{CV}(\%)$ & 8,06 & 11,15 \\
\hline
\end{tabular}

${ }^{1}$ Letras diferentes, na mesma coluna, representam diferença estatística, a $5 \%$, pelo teste Tukey; ${ }^{* *}$ Significativo a 1\%; IVE: índice de velocidade de emergência. 
O índice de velocidade de emergência (IVE) apresentou valores significativos entre os diferentes tipos de frutos. As sementes de frutos vermelhos apresentaram germinação mais rápida, em comparação às sementes de frutos verdes (Tabela 1), demonstrando que a velocidade de germinação das sementes apresenta relação direta com a idade e maturação do fruto. Tal relação pode ser explicada pelo maior vigor e, consequentemente, maior qualidade fisiológica das sementes colhidas de frutos com maior idade (Nakada et al. 2011).

Os valores do teor de água nas sementes, imediatamente após a retirada dos frutos, nos diferentes períodos de armazenamento pós-colheita, variaram de $64,0 \%$ a $45,6 \%$, para os frutos verdes, e de $43,6 \%$ a $42,5 \%$, para os frutos vermelhos (Tabela 2). Desta maneira, observou-se que o armazenamento de frutos acarreta em lenta diminuição nos conteúdos de água da semente, com o avanço da maturação, indicando o preparo do metabolismo da semente, rumo à maturidade fisiológica. Resultados semelhantes foram obtidos em outros frutos carnosos, como mamão (Aroucha et al. 2005) e pepino (Nakada et al. 2011).

Pelos dados da primeira contagem da emergência, realizada aos 7 DAS, verificou-se que, para as sementes retiradas de frutos verdes e vermelhos que permaneceram armazenados até 14 dias, não houve germinação (Figura 1a). O período de armazenamento pós-colheita passou a ser efetivo a partir do vigésimo primeiro dia, ocorrendo emergência na primeira contagem, tanto nas sementes de frutos verdes como vermelhos, indicando um maior vigor das mesmas.

De acordo com Belletti \& Quagliotti (1989) e Queiroz et al. (2011), a percentagem de sementes de espécies de pimenta que não germinam até os 14 dias após a semeadura é alta, sendo necessários períodos de até 45 dias, para a germinação satisfatória de um lote. Desta maneira, pôde-se inferir que um maior período de armazenamento pós-colheita dos frutos é importante para diminuir o tempo de emergência das sementes de pimenta jalapenho, após a semeadura em bandejas, durante a etapa de formação de mudas.
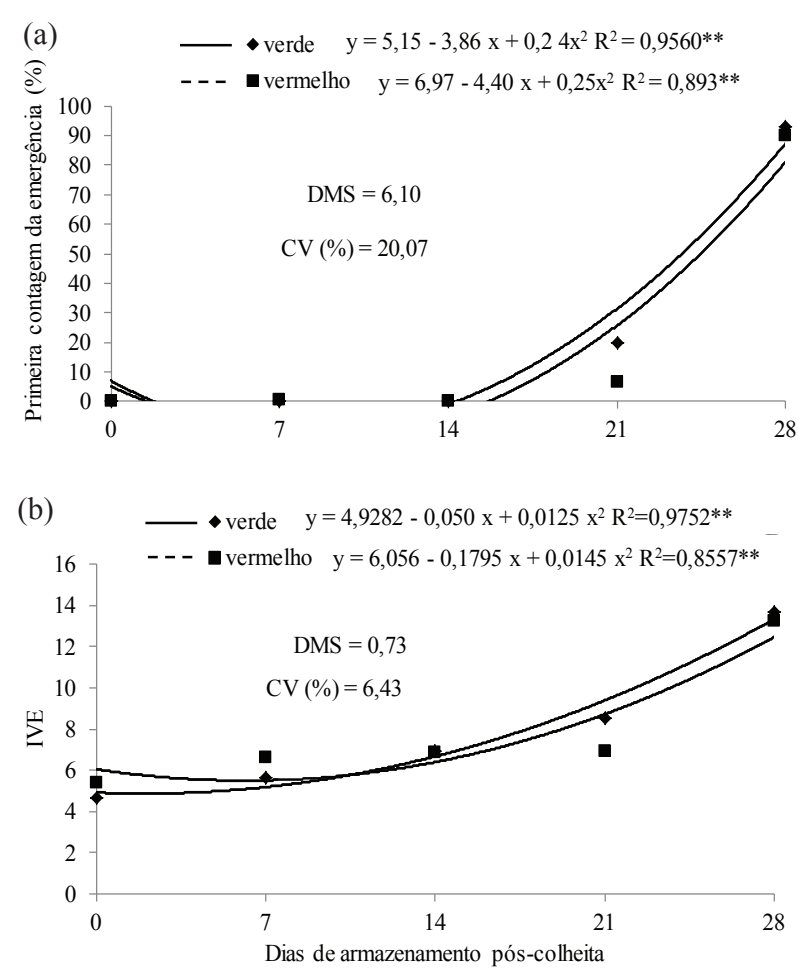

Figura 1. Interação entre os fatores estádio de maturação e período de armazenamento pós-colheita dos frutos, sobre a primeira contagem da emergência (PC\%) e o índice de velocidade de emergência (IVE) de sementes de pimenta jalapenho (Presidente Prudente, SP, 2012). DMS = diferença mínima significativa; $\mathrm{CV}=$ coeficiente de variação.

O armazenamento dos frutos por 28 dias resultou na máxima emergência, por ocasião da primeira contagem, tanto para frutos verdes como para frutos vermelhos (Figura 1a). Este período ainda proporcionou percentagens de emergência significativamente iguais, nas sementes de frutos verdes e vermelhos, revelando-se satisfatório para a manutenção da qualidade das sementes. Períodos excessivos de armazenamento pós-colheita dos frutos, nas colheitas mais tardias, resultam em menor germinação, pelo início da deterioração de suas sementes (Barbedo et al. 1999).

Em relação ao índice de velocidade de emergência (IVE), para as sementes provenientes de

Tabela 2. Grau de umidade das sementes de pimenta jalapenho, em função do estádio de maturação dos frutos e diferentes períodos de armazenamento pós-colheita dos frutos (Presidente Prudente, SP, 2012).

\begin{tabular}{lccccc}
\hline \multicolumn{1}{c}{ Maturação } & 0 dias & 7 dias & 14 dias & 21 dias & 28 dias \\
\hline Fruto verde & 64,0 & 51,00 & 46,2 & 50,0 & 45,6 \\
Fruto vermelho & 43,6 & 45,02 & 45,2 & 45,5 & 42,5 \\
\hline
\end{tabular}


frutos vermelhos, constatou-se germinação mais rápida, quando comparada com a de frutos verdes, para os períodos de armazenamento de 0 e 7 dias (Figura 1b). A semelhança na velocidade de emergência das sementes, para os dois tipos de fruto, ocorreu somente após 10,5 dias de armazenamento pós-colheita dos mesmos. A partir deste período, as sementes provenientes de frutos verdes passaram a germinar mais rapidamente do que as originárias de frutos vermelhos (Figura 1b). Este resultado concorda com o obtido em pimenta 'Amarela Comprida', por Vidigal et al. (2009), cujo efeito do armazenamento pós-colheita dos frutos no vigor das sementes foi mais pronunciado para os frutos colhidos em estádio inicial de maturação (50 dias após a antese), uma vez que sementes obtidas de frutos colhidos nesta época e não armazenados apresentaram baixo vigor.

Dessa forma, evidenciou-se que um tempo adequado de armazenamento dos frutos de pimenta jalapenho torna-se necessário para que a semente alcance a maturidade fisiológica. Neste experimento, tal efeito mostrou-se independente do estádio de desenvolvimento do fruto, no momento da colheita.

De acordo com Sanchez et al. (1993), em sementes de pimentão, mesmo em frutos colhidos maduros e apresentando coloração vermelha, a germinação foi beneficiada pela permanência das sementes no interior do fruto por períodos de até 28 dias. Em frutos de mamão cv. Golden, também foi verificado aumento significativo na germinação das sementes, independentemente da época de colheita dos frutos (Aroucha et al. 2005).

$\mathrm{Na}$ avaliação da emergência total (aos 21 DAS), não foi verificada interação significativa entre os fatores estádio de maturação e período de armazenamento dos frutos (Figura 2a). Observando-se os períodos de armazenamento dos frutos, verificou-se tendência quadrática no incremento da emergência total, até o período de 23 dias de armazenamento pós-colheita de frutos, para máxima emergência estimada em $97,9 \%$.

Tanto as sementes provenientes de frutos verdes como vermelhos atingiram médias de emergência idênticas, no final do período de avaliação (média de $92,3 \%$ ), evidenciando que o estádio de maturação do fruto não influenciou neste resultado.

Os valores de condutividade elétrica das sementes provenientes de frutos verdes apresentaram tendência linear decrescente, em relação ao aumento no período de armazenamento pós-colheita dos frutos
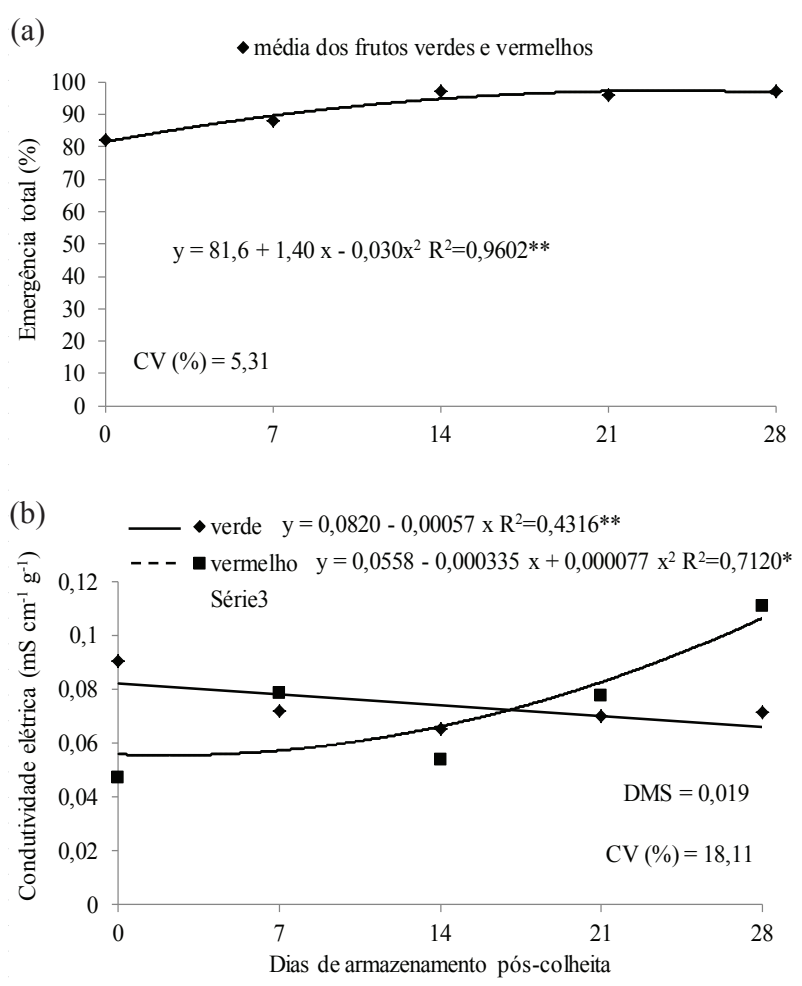

Figura 2. Interação entre os fatores estádio de maturação e período de armazenamento pós-colheita dos frutos, sobre a emergência total e a condutividade elétrica de sementes de pimenta jalapenho (Presidente Prudente, SP, 2012). DMS = diferença mínima significativa; $\mathrm{CV}=$ coeficiente de variação.

(Figura 2b). Sementes colhidas antes da completa maturação do fruto apresentaram elevada perda de lixiviados, justificada pela maior desorganização do sistema de membranas. Com a completa maturação e organização do sistema de membranas da semente, os valores de condutividade elétrica decresceram, indicando aumento de vigor. Este mesmo comportamento foi observado em sementes de soja, por Trzeciak (2012).

Já as sementes retiradas de frutos vermelhos apresentaram ajuste quadrático e maior valor de condutividade elétrica, em relação às sementes provenientes de frutos verdes, aos 28 dias de armazenamento pós-colheita, evidenciando o processo de envelhecimento das mesmas, devido à maturação do fruto. Desta maneira, o aumento do tempo de permanência das sementes no interior dos frutos já maduros pode resultar em comprometimento na qualidade das sementes.

A partir da maturidade fisiológica, inicia-se, de maneira progressiva, o processo de deterioração das 
sementes, caracterizado por alterações fisiológicas, bioquímicas, físicas e citológicas, que determinam a queda na sua qualidade (Marcos Filho 2005). Resultados semelhantes foram encontrados por Nakada et al. (2011) e Demir \& Ellis (1992), em sementes de pepino e tomate, respectivamente, colhidas em diferentes estádios de maturação do fruto, sendo observados menores valores de condutividade elétrica nas sementes oriundas de frutos mais jovens.

\section{CONCLUSÕES}

1. A permanência das sementes de pimenta jalapenho dentro dos frutos, antes da extração, independentemente do grau de maturação (verde ou vermelho), proporcionou aumento de vigor nas sementes.

2. A manutenção das sementes por 28 dias dentro dos frutos colhidos verdes mostrou-se ideal para que as sementes completassem o seu desenvolvimento e adquirissem maior qualidade fisiológica.

\section{REFERÊNCIAS}

AROUCHA, E. M. M. et al. Época de colheita e período de repouso dos frutos de mamão (Carica papaya L.) cv. Golden na qualidade fisiológica das sementes. Ciência Rural, Santa Maria, v. 35, n. 3, p. 537-543, 2005.

BARBEDO, A. S. C. et al. Efeitos da idade e do período de repouso pós-colheita dos frutos sobre a qualidade de sementes de berinjela. Horticultura Brasileira, Brasília, DF, v. 12, n. 1, p. 18-21, 1994.

BARBEDO, C. J. et al. Efeito da idade e do repouso pós-colheita de frutos de pepino na semente armazenada. Pesquisa Agropecuária Brasileira, Brasília, DF, v. 34, n. 5, p. 839-847, 1999.

BELletTI, P.; QUAGLIOTTI, L. Problems of seed production and storage of pepper. In: BELLETTI, P.; QUAGLIOTTI, L. Tomato and pepper productions in the tropics. Taipei: Asian Vegetable Research and Development Center, 1989. p. 28-41.

BRASIL. Ministério da Agricultura, Pecuária e Abastecimento. Regras para análise de sementes. Brasília, DF: MAPA/ACS, 2009.

CASTRO, M. M.; GODOY, A. R.; CARDOSO, A. I. I. Qualidade de sementes de quiabeiro em função da idade e do repouso pós-colheita dos frutos. Ciência e Agrotecnologia, Lavras, v. 32, n. 5, p. 1491-1495, 2008.

COSTA, C. J. ; CARMONA, R.; NASCIMENTO, W. M. Idade e tempo de armazenamento de frutos e qualidade fisiológica de sementes de abóbora híbrida. Revista Brasileira de Sementes, Pelotas, v. 28, n. 1, p. 127-132, 2006.

DEMIR, I.; ELLIS, R. H. Changes in seed quality during seed development and maturation in tomato. Seed Science Research, Cambridge, v. 2, n. 2, p. 81-87, 1992.

DIAS, D. C. F. C. et al. Maturação de sementes de tomate em função da ordem de frutificação na planta. Revista Ceres, Viçosa, v. 53, n. 308, p. 446-456, 2006.

KERBAUY, G. B. Fisiologia vegetal. 2. ed. Rio de Janeiro: Guanabara Koogan, 2008.

LAKSHMANAN, V.; BERKE, T. G. Lack of primary seed dormancy in pepper (Capsicum spp.). Capsicum and Eggplant Newsletter, Turin, v. 17, n. 1, p. 72-75, 1998.

MAGUIRE, J. D. Speed of germination-aid in selection and evaluation for seedling emergence and vigor. Crop Science, Madison, v. 2, n. 2, p. 176-177, 1962.

MARCOS FILHO, J. Fisiologia de sementes de plantas cultivadas. Piracicaba: Fealq, 2005.

MARTINS, G. N. et al. Influência do repouso pós-colheita de frutos na qualidade fisiológica de sementes de mamão. Revista Brasileira de Sementes, Pelotas, v. 28, n. 2, p. 142146, 2006.

NAKADA, P. G. et al. Desempenho fisiológico e bioquímico de sementes de pepino nos diferentes estádios de maturação. Revista Brasileira de Sementes, Pelotas, v. 33, n. 1, p. 113-122, 2011.

NASCIMENTO, W. M.; DIAS, D. C. F.; FREITAS, R. A. Produção de sementes de pimentas. Informe Agropecuário, Belo Horizonte, v. 27, n. 235, p. 30-39, 2006.

QUEIROZ, L. A. F. et al. Época de colheita e secagem na qualidade de sementes de pimenta Habanero Yellow. Revista Brasileira de Sementes, Pelotas, v. 33, n. 3, p. 472481, 2011.

SANCHEZ, V. M. et al. Fruit maturity, storage and postharvest maturation treatments affect bell pepper (Capsicum annuиm L.) seed quality. Scientia Horticulturae, Amsterdam, v. 54, n. 3, p. 191-201, 1993.

SILVA, F. A. S. Assistat. Versão 7.5 beta. Campina Grande: Universidade Federal de Campina Grande, 2010.

SILVA, R. F.; ARAÚJO, E. F.; VIGGIANO, J. Extração de sementes de frutos carnosos de hortaliças. In: NASCIMENTO, W. M. Tecnologia de sementes de hortaliças. Brasília, DF: Embrapa Hortaliças, 2009. p. 77-102.

TRZECIAK, M. B. Formação de sementes de soja: aspectos físicos, fisiológicos e bioquímicos. 2012. $130 \mathrm{f}$. Tese (Doutorado em Fitotecnia) - Universidade de São Paulo, Piracicaba, 2012. 
VIDIGAL, D. O. S. et al. Alterações fisiológicas e enzimáticas durante a maturação de sementes de pimenta (Capsicum annuum L.). Revista Brasileira de Sementes, Pelotas, v. 31, n. 2, p. 129-136, 2009.
VIDIGAL, D. O. S. et al. Qualidade fisiológica de sementes de tomate em função da idade e do armazenamento póscolheita dos frutos. Revista Brasileira de Sementes, Pelotas, v. 28, n. 3, p. 87-93, 2006. 